\title{
Neonatal Stress: Effects of Hypoglycemia and Hypoxia on Adrenal Tyrosine Hydroxylase Gene Expression
}

\author{
JOSEPH D. DECRISTOFARO AND EDMUND F. LAGAMMA \\ Departments of Pediatrics and Neurobiology and Behavior, State University of New York at \\ Stony Brook, Stony Brook, New York 11794-8111
}

\begin{abstract}
Catecholamines (CA) are released from and resynthesized in the adrenal medulla in response to stress. In the mature animal, stimulus-secretion-synthesis coupling occurs through transsynaptic (neuronal) activity. In contrast, in the immature animal, before functional adrenal innervation, certain stressors (hypoglycemia and glycopenia) do not result in CA release. Additionally, it is not known whether release and biosynthesis remain coupled in the neonate as they are in the adult. Therefore, to evaluate whether neonatal stressors can induce CA biosynthesis at the genomic level "directly" before function adrenal innervation, we studied the expression of the tyrosine hydroxylase (TH) gene, the rate-limiting enzyme in CA biosynthesis. Newborn rat pups were made either hypoxic, hypoglycemic, or cellularly glycopenic (2-deoxyglucose). Neither hypoxic stress nor insulin-induced hypoglycemic stress altered steady state levels of TH mRNA in the neonate. However, cellular glycopenia resulted in a significant 2-fold rise in TH mRNA levels $(p<0.05)$. As expected, each of these stressors
\end{abstract}

increased TH mRNA levels in the mature adult rat. Thus, neonatal hypoxia and hypoglycemia appear to require intact neurogenic impulse activity, whereas cellular glycopenia may "directly" induce TH RNA, perhaps through hormonal mechanisms. This developmental model allows for the analysis of mechanisms governing adrenal CA release separate from those governing biosynthesis at the level of TH RNA. Acute neonatal hypoxic stress results in adrenal CA release without increasing TH RNA. Intrauterine growth retardation from chronic prenatal hypoxemia results in neonatal CA depletion and decreased CA responsiveness. We speculate that chronic hypoxia alters CA pathways, increasing the susceptibility of these infants to later stressors. (Pediatr Res 36: 719-723, 1994)
TH, tyrosine hydroxylase
Abbreviations
2-DG, 2-deoxyglucose
CA, catecholamine

Adrenomedullary release of CA are important mediators of two common stressors that compromise the neonatal transition to extrauterine life: hypoxia and hypoglycemia (1-5). In the absence of the adrenal medulla, the fetus and newborn show maladaptive responses resulting in increased morbidity and mortality (6-8). Because functional innervation of the rat adrenal medulla occurs after the first postnatal week of life (9-11), a developmental window exists whereby the direct effects of stressors can be examined, independent of neuronal impulse activity.

Hypoxia, insulin-induced hypoglycemia, and 2-DGinduced glycopenia act transsynaptically to release adrenal CA in the adult (12-15). On the other hand, in the neonatal rat during the first week of life, hypoglycemic

Received June 8, 1993; accepted May 20, 1994.

Correspondence and reprint requests: Joseph D. DeCristofaro, M.D., Department of Pediatrics, HSC T11-060, SUNY at Stony Brook, Stony Brook, NY 11794-8111.

Supported by National Science Foundation Grant 8719872, National Institutes of Health Grant RR05736, and the March of Dimes. stress fails to result in significant CA release, as presynaptic nerve terminals are nonfunctional at that time (10$12,14,16)$. In contrast, at this same age neonatal hypoxia releases CA through a nonneurogenic mechanism, acting "directly" on the adrenal medulla $(11,14,17-19)$. This suggests that the dual roles of transsynaptic activity (regulation of transmitter release and regulation of transmitter biosynthesis) may be functionally separated in the neonate. In the adult, cold stress-induced CA release (and thus depletion of CA stores) results in new CA biosynthesis by activating TH enzyme activity and by increasing the levels of TH mRNA $(20,21)$. Because neonates do not have functional synapses, we sought to determine whether the stressors hypoxia, hypoglycemia, or cellular glycopenia could directly affect CA biosynthesis by changing levels of TH mRNA at a time when transsynaptic neurogenic mechanisms were nonfunctional. We hypothesized that only hypoxic stress would result in an increase in TH mRNA because it is the only 
one of these stressors that may act directly on the adrenal medulla to release significant amounts of CA in the neonate $(14,18,19)$. Surprisingly, we found that TH gene expression was not affected by hypoxic stress, indicating that hypoxia-induced release (nonneurogenic) and biosynthesis could be functionally separated in the first postnatal week of life. As expected, hypoglycemia (a neurogenic-dependent response) did not augment $\mathrm{TH}$ mRNA levels in the absence of functional nerve terminals. Unexpectedly, cellular glycopenia did result in increased neonatal TH mRNA levels. These differences may help characterize the basis of adrenomedullary signal transduction mechanisms affecting stimulus-secretion-synthesis coupling and may help explain the maladaptive responses reported in neonates with asphyxia, hypoxia, and intrauterine growth retardation.

\section{METHODS}

Animal treatments. After a protocol of Seidler and Slotkin $(14,19)$, 4-d-old Sprague-Dawley rat pups from two litters were randomized to two groups of 10: hypoxia or room-air controls. For $2 \mathrm{~h}$, all pups were separated from their dams, maintained at $25^{\circ} \mathrm{C}$, and exposed to either room air or 0.07 to 0.08 fractional inspired oxygen by a constant flow of nitrogen gas. All pups were returned to their assigned dams and decapitated $24 \mathrm{~h}$ later. Medullae were microdissected as previously described (22) and total RNA extracted as previously described $(22,23)$.

To induce hypoglycemia, 4-d-old rat pups from three litters were randomized to one of three groups of 10 : control unmanipulated (To), saline vehicle, or insulin as described by us (22) and Lau et al. (12). Rat pups were treated with $20 \mathrm{U} / \mathrm{kg}$ s.c. of regular insulin (Novolin, Novo Nordisk, $\mathrm{NJ}$ ) or an equal volume of saline vehicle and placed back with their dams after $2 \mathrm{~h}$ as we previously described (22). This treatment resulted in significant neonatal hypoglycemia $(12,16)$. The pups were decapitated $24 \mathrm{~h}$ after injection, adrenal medullae were microdissected, and total RNA was extracted. For comparison, 15 adult male Sprague-Dawley rats weighing 150 to $200 \mathrm{~g}$ were fasted overnight and treated with either nothing, saline vehicle, or $10 \mathrm{U}$ regular insulin as we and others previously described $(22,24)$. After $2 \mathrm{~h}$, insulintreated rats were rescued with $40 \%$ sucrose solution, 2 $\mathrm{mL}$ intraperitoneally and $1 \mathrm{~mL}$ orally. Animals were dissected 24 and $48 \mathrm{~h}$ later and medullae were isolated for RNA extraction.

To induce cellular glycopenia, 4-d-old rat pups from three litters were randomized to three groups of 10 : control unmanipulated (To), saline vehicle, or 2-deoxyglucose (2-DG, Sigma Chemicals, MO) $500 \mathrm{mg} / \mathrm{kg}$ s.c. At this dosage, 2-DG causes a centrally mediated sympathetic stimulation and CA release in mature rats $(13,15$, 21). All rats were decapitated $24 \mathrm{~h}$ after injection, medullae were microdissected, and total RNA was extracted for Northern analysis. For comparison, 15 adult male Sprague-Dawley rats were fasted overnight and treated with either nothing, saline vehicle, or $2-D G 500 \mathrm{mg} / \mathrm{kg}$ and allowed to eat after $2 \mathrm{~h}$ as we previously described (22). No resuscitation was necessary for these rats. All animals were killed $24 \mathrm{~h}$ later, and adrenal medullae were removed for RNA extraction.

Molecular techniques. Total RNA was extracted using minor modifications of the acid guanididium thiocyanate phenol chloroform method $(23,25)$ and quantified by UV spectroscopy as previously described (22). Ten micrograms of total RNA were fractionated on a glyoxal denaturing gel, electrotransferred to a nylon filter, UV crosslinked, baked for $2 \mathrm{~h}$ at $80^{\circ} \mathrm{C}$, and prehybridized overnight (22). Prehybridizing and hybridizing conditions were as previously described (22). After washing and autoradiography, the image intensities were quantified as previously described (22).

A KpnI-PstI 282 bp fragment of the plasmid pTH. ${ }_{4}$ [kindly provided by E. Lewis, Oregon University, Portland, OR (26), and which contains the coding region for the rat TH gene] was radiolabeled with $\left[\alpha^{32} \mathrm{P}\right] \mathrm{dCTP}$ to a sp act of $>10^{9} \mathrm{cpm} / \mu \mathrm{g}$ using standard random primer kits (Boehringer-Mannheim, IN, or Stratagene, CA) (22). As an RNA-loading control, filters were reprobed to the constitutively expressed gene for glyceraldehyde 3-phosphate dehydrogenase, using a Pst I 1269-bp fragment of the plasmid $\mathrm{pR}$-glyceraldehyde 3-phosphate dehydrogenase-13 (provided by K. Marcu, State University of New York, Stony Brook, NY) (27).

Statistics. Each of these experiments was performed three times. A $t$ test was performed in analyzing the hypoxia experiments. Analysis of variance followed by Neuman-Keuls test was used for the insulin and 2-DG experiments. A $p$ value of $<0.05$ was considered significant (28).

\section{RESULTS}

Exposing neonatal rat pups to hypoxia for $2 \mathrm{~h}$, a treatment that results in CA release directly through a nonneurogenic mechanism, did not result in increased adrenal TH mRNA levels, as seen in Figure 1. Neonatal pups treated with insulin to induce hypoglycemia, a treatment that results in no significant release of adrenal CA at this age (it requires functional transsynaptic activity), also exhibited no resulting increase in TH mRNA levels, as seen in Figure 2. When pups were made glycopenic with 2-DG, a treatment that also results in no significant release of adrenal $\mathrm{CA}$, the result was a 2-fold rise in $\mathrm{TH}$ mRNA levels $(p<0.05)$, as seen in Figure 3 . In contrast to these studies in pups, when mature rats are exposed to these stressors, TH mRNA increased as expected 1.5fold after insulin shock at $24 \mathrm{~h}$ and 1.7 -fold after $48 \mathrm{~h}(p$ $<0.05$ versus control and saline), as seen in Figure 4. Adult rats treated with 2-DG had TH mRNA levels 2.2 times that of controls $(p<0.05)$. Similar results were obtained when using either $18 \mathrm{~S}$ ribosomal RNA as a loading control or expressing the results as TH RNA per total RNA loaded. 


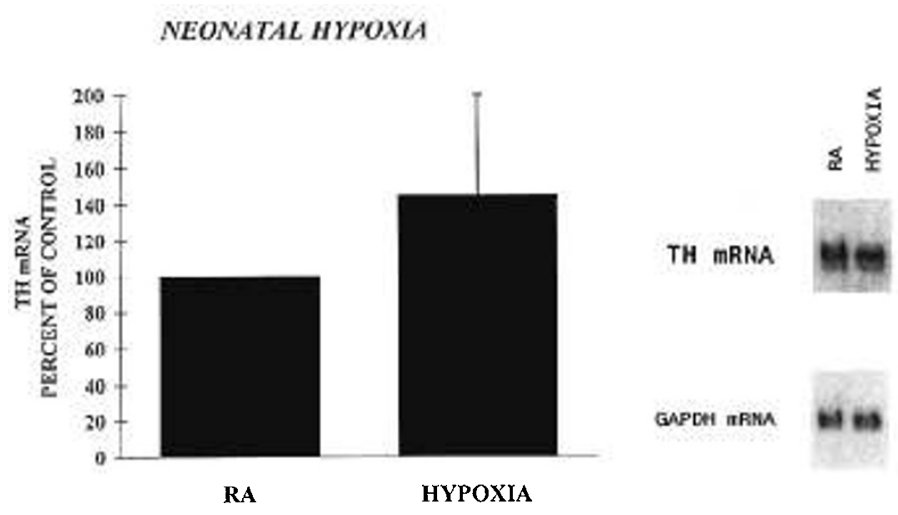

Figure 1. Effect of neonatal hypoxia on TH gene expression. Newborn rat pups were exposed to hypoxia ( 0.07 to 0.08 fraction of inspired oxygen) for $2 \mathrm{~h}$ at $4 \mathrm{~d}$ of life (at a time before functional innervation to the adrenal medulla). Although this stress results in a significant release of catecholamines, there was no significant increase in adrenal $\mathrm{TH}$ mRNA levels as determined by Northern blot analysis compared with room-air $(R A)$ controls.

\section{DISCUSSION}

CA are essential for the successful transition to extrauterine life $(6-8,18,29)$. At birth, the CA surge is largely due to their release from the adrenal medulla $(8,29)$ and occurs primarily in response to hypoxic stress and other factors active at delivery $(7,8,18,29)$. As innervation to the adrenal medulla is incomplete in the rat fetus and newborn, hypoxic stress results in CA release "directly" through nonneurogenic mechanisms $(8,9,18)$. This nonneurogenic release may be a direct effect of hypoxia on the chromaffin cells, or it may be acting through hormones released from this stress. For example, prolactin, corticosteroids, and angiotensin II each have been shown to regulate CA release in cultured fetal chromaffin cells (30). Later, after functional innervation to the adrenal medulla is complete, these nonneurogenic mechanisms are no longer active, and hypoxia results in CA release by a centrally mediated sympathetic innervation [as ganglionic blockade with chlorosondamine prevents this release $(8,14)]$. In contrast, insulin-induced hypoglycemia and 2-DG-induced glycopenia result in adrenal CA re-

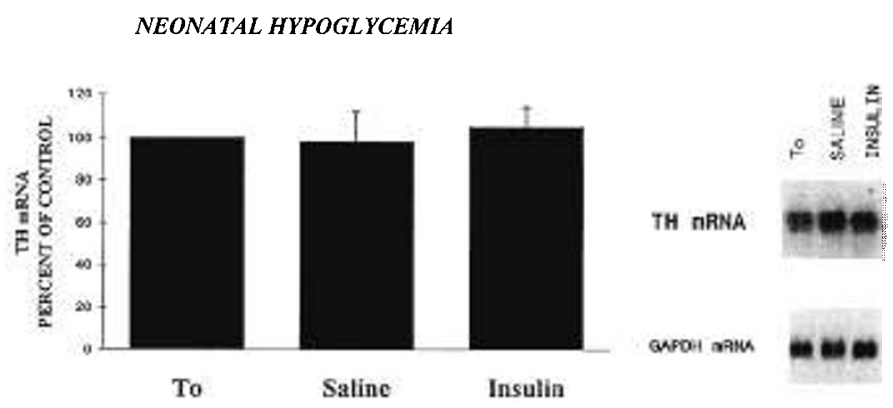

Figure 2. Effects of neonatal hypoglycemia on TH gene expression. Insulin-induced hypoglycemia in neonatal rats results in no significant catecholamine release, and Northern analysis shows no significant difference in adrenal TH mRNA levels compared with unmanipulated controls $(T o)$ or saline vehicle.

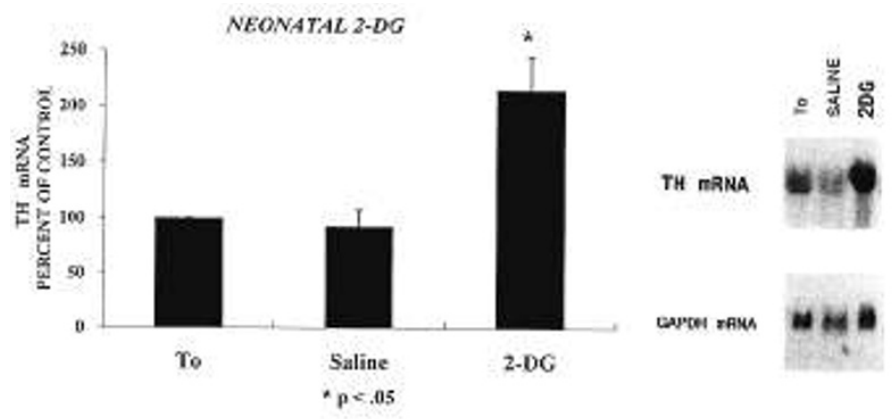

Figure 3. Effects of neonatal glycopenia on TH gene expression. Neonatal rats treated with $2-D G$ results in no significant catecholamine release, but Northern analysis shows a significant 2 -fold rise $(p<0.05)$ in TH mRNA compared with unmanipulated controls (To) or saline vehicle.

lease only in the presence of functional innervation, as this response is a centrally mediated transsynaptic event.

Although neonatal hypoxia results in CA release "directly" (through a nonneurogenic mechanism), we found no increase in steady state TH mRNA levels in the adrenal medulla. This suggests that there was an uncoupling of release and biosynthetic mechanisms at this age, at least at the level of TH RNA. Alternatively, hypoxia may have resulted in $\mathrm{TH}$ activation without increasing
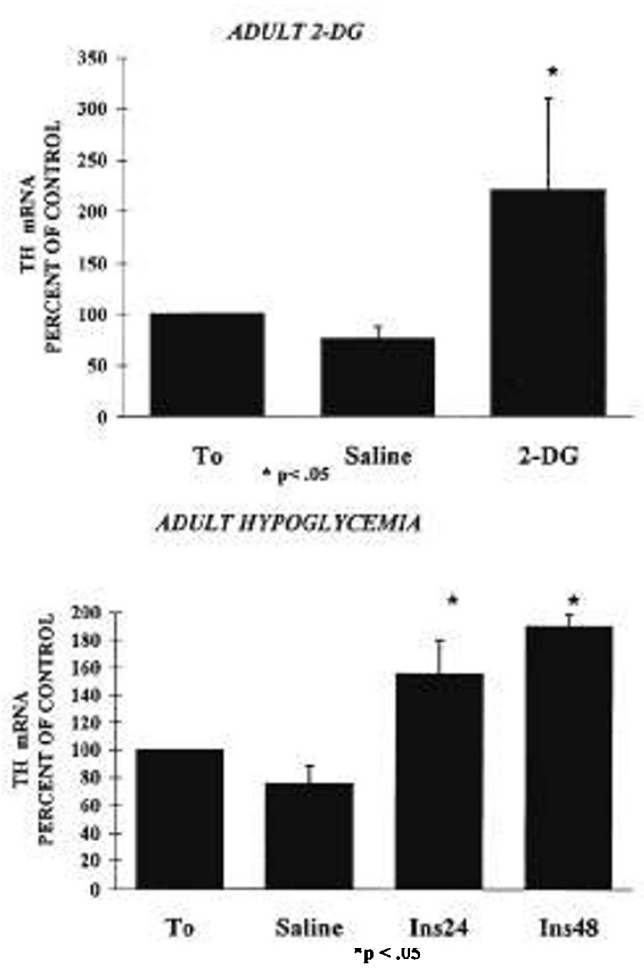

Figure 4. Effects of glycopenic and hypoglycemic stress on TH gene expression in the adult rat. Top, Adult rats were made glycopenic with 2-DG and controls treated with saline vehicle. TH mRNA was significantly elevated $(p<0.05)$ after 2-DG treatment, compared with saline vehicle or unmanipulated control (To) Bottom, A single hypoglycemic stress in the adult rat resulted in a significant $(p<0.05)$ elevation in $\mathrm{TH}$ mRNA levels 24 and $48 \mathrm{~h}$ after insulin injection, compared with saline vehicle and unmanipulated control $(T o)$. There was no difference between TH mRNA levels at 24 and $48 \mathrm{~h}$ after insulin injection. Hypoxemia was previously reported to have no significant change in adrenal TH mRNA levels in the adult rat (31). 
TH RNA; however, we did not measure TH protein or TH activity. Moreover, it is well recognized that the neonatal rat pup can respond to cholinergic receptor agonists $(8,19)$ with release of $\mathrm{CA}$, increased adrenal TH activity (8), and enkephalin content (31), consistent with functional extracellular receptors coupled to intracellular cholinergic-linked second-messenger systems. Ultimately, hypoxia-induced CA release without new biosynthesis would represent a maladaptive response, as the net result would be CA depletion.

The release of CA from the adrenal have been shown to be critical for the neonatal adaptive response to postnatal stress and, in particular, for pups to survive hypoxic stress $(7,8,14,18,29)$. For example, adrenalectomized rats that are hypoxia-stressed have a greater mortality $(70$ versus $20 \%$ control), independent of steroid replacement, illustrating the critical need for CA (6). In the case of the chronically stressed intrauterine growth-retardation model of Wigglesworth (32), CA release and biosynthetic mechanisms appear to be deficient. In the intrauterine growth-retardation-model animal, CA release is eventually attenuated in response to acute hypoxia and biosynthesis is not stimulated as compared with control (17), making these animals more vulnerable to postnatal stress. This would suggest that chronic prenatal hypoxic stress has significant long-term postnatal effects on CA pathways.

In the adult adrenal, hypoxia results in increased $\mathrm{TH}$ activation (33) but does not increase in TH mRNA (34). On the other hand, in the adult rat carotid body, hypoxia acts directly to increase TH mRNA in a dose-responsive manner (34) and also augments CA biosynthesis (35). The TH gene may well have a hypoxia-sensitive element with a consensus sequence similar to that of the erythropoietin gene (36) that responds to low $\mathrm{PO}_{2}$ in the carotid body and $\mathrm{PC1} 2$ (rat pheochromocytoma) cells. Because the $\mathrm{Po}_{2}$ in the fetus is very low already, alterations in $\mathrm{TH}$ gene expression in response to hypoxia in the neonate may be dampened, or the response may be tissue-specific or cell-specific (34).

In hypoglycemic stress, Khalil et al. (3) have described a two-stage response in the adult rat. The first part is neurogenic (early), whereas the second part (late) involves a nonneurogenic mechanism that could not be blocked by cholinergic antagonists (3). This nonneurogenic late component occurred when the serum blood sugar level fell below $75 \mathrm{mg} / \mathrm{dL}$ and may represent a hormonal response (3). In the neonatal rat, as expected, before functional innervation, we found that transsynaptically mediated hypoglycemic stress failed to alter CA biosynthesis at the level of TH mRNA (Fig. 2). Using this protocol $(12,16)$, the level of hypoglycemia was well below the threshold described by Khalil $(75 \mathrm{mg} / \mathrm{dL})$. Thus, this late, nonneurogenic pathway may also be unresponsive or nonfunctional in the neonatal rat pup exposed to hypoglycemia.

Interestingly, in contrast to insulin-induced hypoglycemia, 2-DG-induced cellular glycopenia, which does not result in CA release in the newborn, did result in a significant 2-fold rise in TH mRNA levels (Fig. 3). Thus, cellular glycopenic stress appears to be sufficient to induce $\mathrm{TH}$ gene expression at a time before functional neuronal innervation. Alternatively, because 2-DG treatment results in high serum glucose levels and insulin treatment in low glucose levels, the hormonal responses differ. Together, the data best support the conclusion that 2-DG is nonneurogenic and probably a hormonal response or may be some other direct pharmacologic effect of 2-DG. In any case, neonatal 2-DG treatment may be useful as a model to separate nonneurogenic or hormonal mechanisms that result in increased TH mRNA (e.g. biosynthesis) independent of those neurogenic (transsynaptic) stimuli that result in CA release.

In adult rats, hypoglycemic stress results in $\mathrm{TH}$ activation $(20,21)$ and increased TH mRNA for at least $2 \mathrm{~d}$ after the stress (Fig. 4). Glycopenia with 2-DG, which is known to increase sympathetic drive, was also associated with increased TH mRNA in the adult. This effect may also have a nonneurogenic component as well which may be hormonal (e.g. glucagon, etc.). Glucocorticoids are unlikely to be involved, as each of these stressors result in corticosteroid release in the neonate as well as in the adult $(15,38)$. Thus, it is doubtful that any increase in TH mRNA after 2-DG treatment can be attributed to glucocorticoids alone; other hormonal mechanisms are likely to be involved.

Our data suggest that the newborn rat is better suited to respond (or adapt) to acute hypoxic stress by CA release than to hypoglycemia (neither CA release nor biosynthesis). This may represent a teleologic adaptation, as the birthing process frequently results in a transient hypoxemia and very infrequently in hypoglycemia. The corresponding period of noninnervated adrenal medulla in humans is approximately 23 wk (39), suggesting that the first- and second-trimester fetus may be particularly vulnerable to the direct effects of hypoglycemic stress.

In summary, we found that stressors that induce CA release and biosynthesis in the adult rat do not induce $\mathrm{CA}$ pathways in parallel in the neonate. Neonatal hypoxia results in CA release, but not in CA biosynthesis at the level of TH RNA. Only neonatal glycopenia resulted in a significant rise in TH mRNA. We speculate that these nonneurogenic mechanisms are hormone-based and that the newborn rat offers a developmental model in which to access the direct effects of stressors on the adrenal medulla, independent of neurogenic mechanisms, and that using this paradigm one may study mechanisms of release separate from biosynthesis.

\section{REFERENCES}

1. Axelrod J, Reisine TD 1984 Stress hormones: their interaction and regulation. Science 224:452-459

2. Johnson TS, Young JB, Landsberg L 1983 Sympathoadrenal responses to acute and chronic hypoxia in the rat. J Clin Invest 71:1262-1272

3. Khalil Z, Marley PD, Livett BG 1986 Elevation in plasma catecholamines in response to insulin stress is under both neurogenic and non-neurogenic control. Endocrinology 119:159-167 
4. Lau C, Ross LL, Whitmore WL, Slotkin TA 1987 Regulation of adrenal chromaffin cell development by the central monoaminergic system: differential control of norepinephrine and epinephrine levels and secretory responses. Neuroscience 22:1067-1075

5. Stachowiak MK, Fluharty SJ, Stricker EM, Zigmond MJ, Kaplan BB 1986 Molecular adaptations in catecholamine biosynthesis induced by cold stress and sympathectomy. J Neurosci Res 16:13-24

6. Lagercrantz H, Slotkin TA 1986 The stress of being born. Sci Am 254:100-107

7. Slotkin TA, Seidler FJ 1983 Role of adrenomedullary catecholamine release in survival during neonatal hypoxia. Prog Neuropsychopharmacol Biol Psychiatry (suppl): $41-42$

8. Slotkin TA, Seidler FJ 1988 Adrenomedullary catecholamine release in the fetus and newborn: secretory mechanisms and their role in stress and survival. J Dev Physiol 10:1-16

9. Slotkin TA 1986 Development of the sympathoadrenai axis. In: Gootman PM (ed) Developmental Neurobiology of the Autonomic Nervous System. Humana Press, Clifton, NJ, pp 69-96

10. Slotkin TA, Chantry CJ, Bartolome J 1984 Development of central control of adrenal catecholamine biosynthesis and release. In: Zumi FI, Oka M, Kumakura K (eds) Advances in Bioscience: Synthesis, Storage, and Secretion of Adrenal Catecholamines. Pergamon Press, Elmford, NY, pp 95-102

11. Smith PG, Slotkin TA, Mills E 1982 Development of sympathetic ganglionic neurotransmission in the neonatal rat: pre- and post-ganglionic nerve response to asphyxia and 2-deoxyglucose. Neuroscience 7:501-507

12. Lau C, Bartolome JV, Bartolome MB, Slotkin TA 1987 Central and sympatho-adrenal responses to insulin in adult and neonatal rats. Dev Brain Res 36:277-280

13. Niijima A 1975 The effect of 2-deoxy-D-glucose and D-glucose on the efferent discharge rate of sympathetic nerves. J Physiol 251:231-243

14. Seidler FJ, Slotkin TA 1986 Ontogeny of adrenomedullary responses to hypoxia and hypoglycemia: role of splanchnic innervation. Brain Res Bull 16:11-14

15. Sun CL, Thoa NB, Kopin IJ 1979 Comparison of the effects of 2-deoxyglucose and immobilization on plasma levels of catecholamines and corticosterone in awake rats. Endocrinology 106:306-311

16. Souto M, Piezzi RS, Bianchi R 1988 Catecholaminergic responses of neonatal adrenal glands to insulin. J Neural Transm 73:115-120

17. Shaul PW, Cha C-JM, Oh W 1989 Neonatal sympathoadrenal response to acute hypoxia: impairment after experimental intrauterine growth retardation. Pediatr Res 25:466-472

18. Seidler FJ, Slotkin TA 1985 Adrenomedullary function in the neonatal rat: responses to acute hypoxia. J Physiol 358:1-16

19. Seidler FJ, Slotkin TA 1986 Non-neurogenic adrenal release in the neonata rat: exocytosis or diffusion? Dev Brain Res 28:274-277

20. Fluharty SJ, Synder GL, Stricker EM, Zigmond MJ 1983 Short- and long term tyrosine hydroxylase activity during insulin-induced hypoglycemia and cold stress. Brain Res 267:384-387

21. Fluharty SJ, Synder GL, Zigmond M, Stricker EM 1985 Tyrosine hydroxylase activity and catecholamine biosynthesis in the adrenal medulla of rat during stress. J Pharmacol Exp Ther 233:32-38

22. LaGamma EF, Agarwal BL, DeCristofaro JD 1992 Regulation of adrenomedullary preproenkephalin mRNA: effects of hypoglycemia during development. Mol Brain Res 13:189-197
23. Weisinger G, DeCristofaro JD, LaGamma EF 1992 Determination of transcriptional start sites and their usage in the nervous system. In: Longstaff $A$, Revest P (eds) Methods in Molecular Biology, Vol 13: Protocols in Molecular Neurobiology. Humana Press, Totowa, NJ, pp 115-138

24. Kanamatsu T, Unsworth CD, Dilberto EJ, Viveros OH, Hong JS 1986 Reflex splanchnic nerve stimulation increases levels of proenkephalin A mRNA and proenkephalin A-related peptides in the rat adrenal medulla. Proc Natl Acad Sci USA 83:9245-9249

25. Chomczynski P, Sacchi N 1987 Single step method of RNA isolation by acid guanidinium thiocyanate-phenol-chloroform extraction. Anal Biochem 162:156-159

26. Lewis E, Tank AW, Weiner N, Chikaraishi DM 1983 Regulation of tyrosine hydroxylase mRNA by glucocorticoids and cyclic AMP in a rat pheochromocytoma cell line. J Biol Chem 258:14632-14637

27. Piechaczyk M, Blanchard JM, Marty L, Dani Ch, Panabieres F, El Sabouty S, Fort Ph, Jeantheur Ph 1986 Post-transcriptional regulation of glyceraldehyde 3-phosphate dehydrogenase gene expression in rat tissues. Nucl Acid Res 12:6951-6963

28. Zar JH 1984 Biostatistical Analysis. Prentice-Hall, Englewood Cliffs, NJ

29. Padbury J, Agata Y, Ludlow J, Ikegami M, Baylen B, Humme J 1987 Effect of fetal adrenalectomy on catecholamine release and physiologic adaptation at birth in sheep. J Clin Invest 80:1096-1103

30. Graham ADM, Longo LD, Cheung CY 1986 Catecholamine secretion from the adrenal medulla of the fetus, regulation by hormones. J Dev Physiol 8:227-235

31. DeCristofaro JD, LaGamma EF 1990 Bimodal regulation of adrenal opiate peptides by cholinergic mechanisms. Neuroscience 35:203-210

32. Wigglesworth JS 1964 Experimental growth retardation in the foetal rat. J Pathol Bacteriol 88:1-13

33. Hayashi Y, Miwa S, Koshimura K, Hamahata K, Hasegawa H, Fujiwara M, Watanabe Y 1990 Enhancement of in vivo tyrosine hydroxylation in the rat adrenal gland under hypoxic conditions. J Neurochem 54:1115-1121

34. Czyzyk-Krzeska MF, Bayliss DA, Lawson EE, Millhorn DE 1992 Regulation of tyrosine hydroxylase gene expression in the rat carotid body by hypoxia. J Neurochem 58:1538-1546

35. Gonzalez C, Kwok Y, Gibb JW, Fidone SJ 1979 Effects of hypoxia on tyrosine hydroxylase in the rat carotid body. J Neurochem 33:713-719

36. Norris ML, Czyzyk-Krzeska MF, Millhorn DE 1993 Oxygen signal transduction of transcription if the tyrosine hydroxylase gene by reduced $\mathrm{O}_{2}$ tension in PC12 cells. Soc Neurosci 19:737(abstr)

37. Czyzyk-Krzeska MF, Lawson EE, Millhorn DE 1993 Hypoxia-activated cytoplasmic protein binds to a specific sequence in the $3^{\prime}$ untranslated region of the tyrosine hydroxylase mRNA. Soc Neurosci 19:736(abstr)

38. Zarrow MX, Denenberg VH, Haltmeyer GC, Brumaghin JT 1967 Plasma and adrenal corticosterone levels following exposure of two-day-old rat to various stressors. Proc Soc Exp Biol Med 125:113-116

39. Hamill RW, LaGamma EF 1992 Autonomic nervous system development. In: Banister SR, Mathias CJ (eds) Autonomic Failure. Oxford University Press, Oxford, England 